\title{
Managing patients at risk for age-related macular degeneration: a Canadian strategy
}

\section{ABSTRACT}

Background: To develop a consensus strategy for the management of patients at risk for age-related macular degeneration (AMD) for Canadian ophthalmologists, optometrists and physicians.

Methods: Development of a consensus strategy began with a review of the literature and existing guidelines. A panel of retina specialists, ophthalmologists, and optometrists from across Canada assessed this evidence to distill what was learned and use this knowledge as the basis for developing a consensus strategy for managing patients at risk of AMD.

Results: The expert panel has developed a series of recommendations for Canadian eyecare providers (eg. ophthalmologists, optometrists) and physicians to adopt as a preventive strategy for patients at risk of AMD.

Interpretation: This consensus strategy is a practical guideline that can be adopted in the office setting to manage patients at risk of $A M D$ and to advise patients with questions and concerns about AMD.
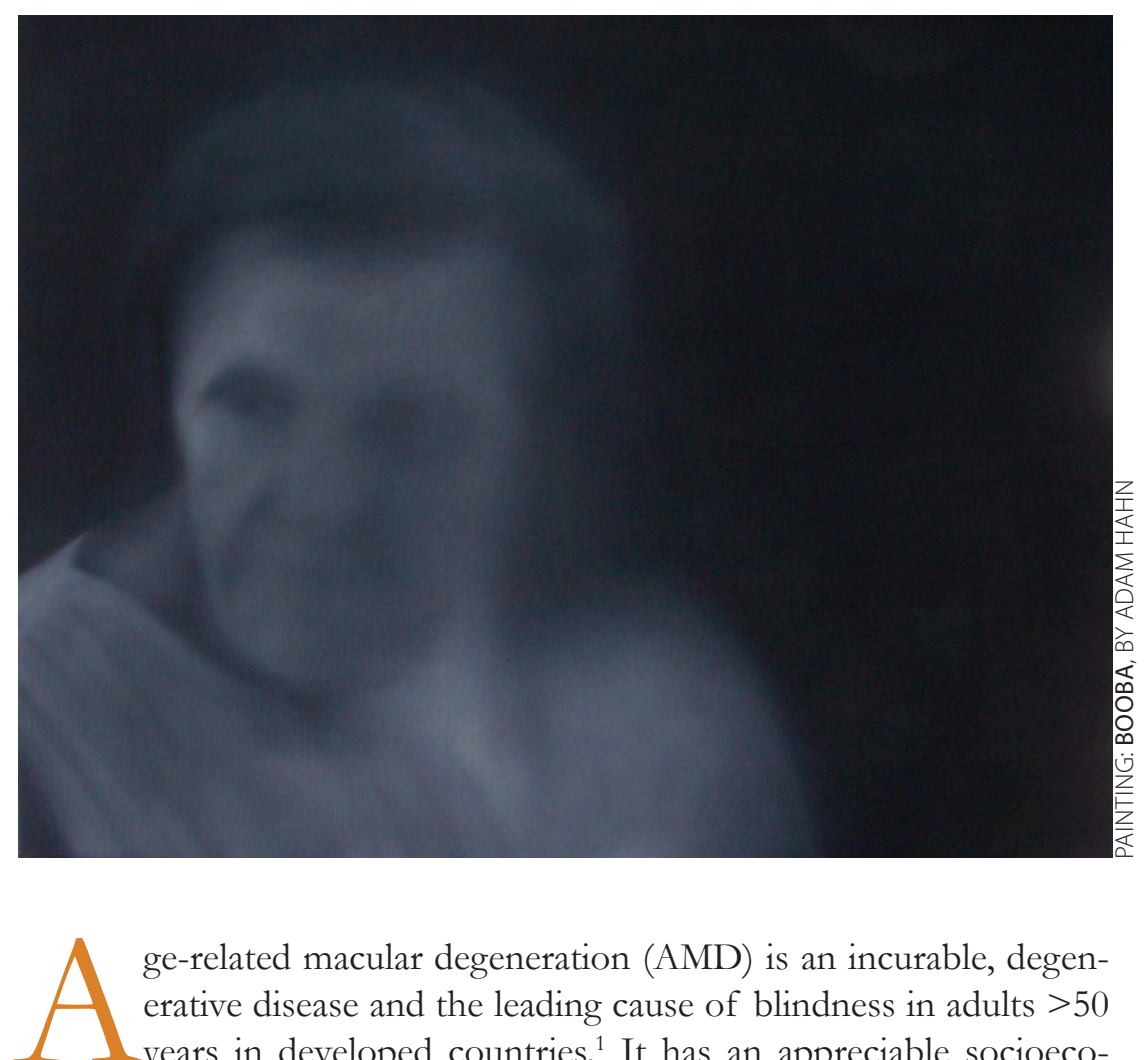

ge-related macular degeneration (AMD) is an incurable, degenerative disease and the leading cause of blindness in adults $>50$ years in developed countries. ${ }^{1}$ It has an appreciable socioeconomic impact that will only increase as our population ages, unless a way is found to prevent AMD or halt its progression.

There are two major types of AMD. Neovascular, also called "exudative" and "wet", AMD is characterized by the development of choroidal neovascular membranes, subretinal hemorrhage and/or fluid, and fibrosis at the advanced stage. The more common form, dry and atrophic, accounts for about $85 \%$ of AMD. It is characterized by drusen and/ or retinal pigment epithelial irregularities, often progressing to atrophic areas. $^{2}$ A small percentage of dry AMD progresses to neovascular AMD. ${ }^{2}$

AMD has a complex natural history that is poorly understood, although various risk factors have been identified. There is no cure for AMD, but 
current developments have made the management of AMD increasingly possible. Furthermore, insights into prevention and risk factors have aided the development of other important management strategies.

In 2007, in Toronto, an expert panel of Canadian ophthalmologists and optometrists met with several objectives:

- to understand the current best practices in managing patients at risk for AMD;

a to understand the current challenges in helping patients at risk in order to reduce the incidence of this debilitating disease and prevent its progression to advanced stages;

- to develop practical guidelines to help to prevent the progression of AMD in at-risk patients.

The purpose of presentations and subsequent discussions at this meeting was to supply background, perspective, and information from the existing literature and clinical practice to serve as a basis for the definition of a consensus strategy for the management of people at risk for AMD.

\section{Incidence and Prevalence of AMD}

No specific figures are available for the prevalence of AMD in Canada; however, it is not unreasonable to extrapolate from an important U.S. initiative: the Beaver Dam Eye Study. During the first study (1988-1990), Klein et $\mathrm{al}^{3}$ determined that signs of age-related maculopathy were present in $8.5 \%$ of people from
43 to 54 years and most common among people $\geq 75$ years $(36.8 \%)$. In the next study (2003-2005), Klein et $\mathrm{al}^{4}$ reported that the 15 -year cumulative incidence of early AMD was $14.3 \%$ in adults $>43$ years; for late AMD, it was $3.1 \%$. Among people $\geq 75$ years, the 15 -year cumulative incidence of late AMD was $8 \%$. Extrapolating the initial findings of the Beaver Eye Dam Study to the Canadian population determines that nearly 2.2 million Canadians may have some stage of AMD (Table 1).

With a decreasing birth rate and increasing life expectancy, the proportion of older Canadian adults is increasing more rapidly than other age groups. ${ }^{5}$ In 2005 , the number of Canadian seniors ( $>65$ years) was projected to increase from 4.2 million to 9.8 million in 2036 , almost doubling the percentage of seniors in the Canadian population from $13.2 \%$ to $24.5 \% .^{5}$

\section{Burden of Illness}

Brown et $\mathrm{al}^{6}$ reported that even a mild case of AMD (20/20 to 20/40 in the better-seeing eye) lessens quality of life for the average patient by $17 \%$, similar to the impact of moderate cardiac angina or symptomatic HIV. Moderate AMD (20/50 to $20 / 100$ in the better-seeing eye) causes a $32 \%$ decrease in quality of life, similar to the impact of severe cardiac angina or a fractured hip. Severe AMD $(\leq 20 / 200$ in the betterseeing eye) decreases quality of life by $53 \%$, which is a greater impact than kidney dialysis. Those with very severe AMD $(\leq 20 / 800$ in the better-seeing eye) reported a $60 \%$ decrease in quality of life, similar to the impact of end-stage prostate cancer or a catastrophic stroke. Of interest, Brown et $\mathrm{al}^{6}$ also reported that ophthalmologists dramatically underestimated the quality of life of patients with moderate and severe AMD.

These authors also reported that wet and dry AMD have an annual negative impact of approximately U.S.\$30 billion on the U.S. gross domestic product. ${ }^{6}$ A more recent economic analysis has estimated the indirect cost of wet AMD as U.S. $\$ 2.5$ billion per year in lost productivity. ${ }^{7}$ For dry AMD, indirect costs are measured at U.S.\$24.4 billion. ${ }^{7}$

\section{Pathogenesis of AMD}

The pathogenesis of AMD is multifactorial, involving genetic and environmental factors. It is associated with interactions in several biological processes, including oxidative stress and inflammation, leading to dysfunction of the retinal pigment epithelium (RPE), Bruchs membrane, and photoreceptor complex. Activation of these processes initiates a chain of events (Figure 1), manifested by the hallmarks of AMD: ${ }^{4}$

- Large numbers of small hard drusen appear between the RPE, Bruchs membrane, and the choroid.

- The drusen become larger and more confluent ("softer"). Pigmentary abnormalities (hyperpigmentation and atrophy) occur and lipofuscin increases in the RPE.

- Over time, central geographic atrophy of the RPE and/or angiogenesis may follow. 


\section{Oxidative stress and antioxidants}

The RPE is a monolayer of unique cells that manages the flow of nutrients to photoreceptors, digests waste (outer rod and cone segments) from photoreceptors, and controls metabolism for the retina. ${ }^{8}$ The retina has high concentrations of oxygen, polyunsaturated fatty acids, and photosensitizers. These substances, combined with light exposure, make the retina susceptible to oxidative stress. ${ }^{9}$ How this works precisely is unknown, but one theory suggests that, as the rate of digestion of outer rod and cone segments decreases within the RPE, lipofuscin formation increases.

A recent study, which found oxidized phospholipids in photoreceptors and RPE cells, reported that the amount of these phospholipids increased with age. ${ }^{10}$ They also found that eyes with AMD were more intensely immunoreactive for oxidized phospholipids than age-matched normal eyes. They concluded that oxidative damage to photoreceptors and RPE cells may be the mechanism for these changes. This conclusion was reinforced by Kamei et $\mathrm{al}^{11}$, who found that macrophages and RPE express cell surface scavenger receptors for oxidized lipoproteins. These studies noted that the pathophysiology of AMD has some similarities to that of atherosclerosis, but the ramifications of this hypothesis have yet to be fully explored.

Oxidative stress can be exacerbated by external factors, particularly smoking and perhaps excessive sun- light exposure. ${ }^{912-14}$ Low levels of antioxidants and minerals upset the natural balance that normally neutralizes free radicals. Free-radical formation appears to impair the RPE's ability to function properly. In the macula, a healthy RPE contains high concentrations of natural antioxidants, such as vitamin $\mathrm{C}$, glutathione, vitamin $\mathrm{E}$, retinoids, carotenoids, and enzymes, such as superoxide dismutase and phospholipid hydroperoxide glutathione peroxidase (PHGPx). In diets with a low antioxidant intake, providing adequate antioxidant supplementation could be a key line of defence.

\section{Specific nutrients in AMD}

The benefits of nutritional supplementation in AMD are rooted in the AREDS trial. ${ }^{12,15,16}$ In this trial, high doses of Vitamins $\mathrm{C}$ and $\mathrm{E}$, zinc, and beta-carotene have shown a benefit in retarding the progression of AMD in patients with moderate to advanced disease.

Lutein and zeaxanthin were not available at the time of the first AREDS trial, so definitive conclusions as to their benefits are still unknown. Both lutein and zeaxanthin, which give the macula a yellow colour, play a protective role as antioxidants and filter short-wavelength light. Various studies suggest a benefit for these carotenoids in the treatment of AMD. Observational data from the AREDS 22, ${ }^{16}$ Blue Mountain Eye Study, ${ }^{17}$ CAREDS, ${ }^{18}$ and POLA ${ }^{19}$ studies have associated a higher dietary intake of carotenoids with a lower incidence of AMD progression. Furthermore,
Seddon et $\mathrm{a}^{20}$ have shown that patients taking $5.8 \mathrm{mg} /$ day of lutein had a $43 \%$ lower risk of wet AMD. AREDS-2 will further define the role of these carotenoids in a randomized, controlled trial.

There is a suggestion that vitamin supplementation may help in the primary prevention of incident AMD. Van Leeuwen et al have specifically established their ability to protect against AMD, finding that "a high dietary intake of beta carotene, vitamins $\mathrm{C}$ and $\mathrm{E}$, and zinc together was associated with a substantially reduced risk of AMD in elderly persons."

This statement seems to contradict a recent meta-analysis in the British Medical Journal, which reported the individual effects of dietary antioxidants on primary prevention of AMD. ${ }^{21}$ It concluded that, individually, insufficient evidence supports the role of dietary antioxidants, including the use of dietary antioxidant supplements, for the primary prevention of early AMD. One limitation of this meta-analysis, which the authors noted, is that they did not look at the effects of antioxidants in combination.

The Rotterdam Study, a prospective cohort study, has compared the effects of antioxidants individually and in combination. It reported that the results for individual antioxidants were not as strong as the benefit reported when all four antioxidant supplements were taken together.' This finding was similar to the AREDS trial, which reported significant reductions in the risk of progression to advanced AMD in 
the antioxidant arm (17\%), zinc arm (21\%), and antioxidant plus zinc $\operatorname{arm}(25 \%$ after 6.3 years and $27 \%$ in the 10 -year extension). ${ }^{15}$ Perhaps benefits in both studies are attributable to the synergistic effects of antioxidants taken in combination rather than isolation.

Another limitation of the metaanalysis is that a large portion of the study population worked in the healthcare industry and therefore may not be indicative of the normal population. ${ }^{21}$

\section{Risk factors}

Precisely how the pathological process in AMD is initiated and progresses is not fully understood, but several risk factors have been identified. They are divisible into two groups: unmodifiable and modifiable.

\section{Unmodifiable risk factors}

Age: The Beaver Dam Eye Study, among others, has established that the incidence and the severity of AMD increase with age. ${ }^{4}$

Genetics: Based on twin and family studies, there appears to be strong evidence for a genetic component in the risk of developing AMD. ${ }^{2,22}$ Recent genome-wide linkage and association studies have focused on finding candidate genes for AMD. Among the loci of interest are 1q32 (complement factor $\mathrm{H}$ gene) and a region of 10q26 (LOC387715). Although the exact mechanism of how these single nucleotide polymorphisms lead to AMD is unknown, they appear to play a part in the inflammatory cascade and oxidative stress models of injury, respectively. ${ }^{23}$

Gender: Women are at slightly higher risk of having one or more intermediate drusen, extensive small drusen, or RPE pigmentary abnormalities. ${ }^{12}$

Race: AREDS 3 found a higher frequency of choroidal neovascularization among Caucasians, who had a higher frequency of one or more large drusen $(>125 \mu \mathrm{m})$ and extensive intermediate drusen. ${ }^{12}$ The authors speculated that increased melanin in RPE cells, acting as a free radical scavenger or simply as a filter for ultraviolet radiation, protects the RPE cells and Bruchs membrane, reducing the risk of developing large drusen and RPE pigmentary changes and therefore reducing the risk of geographic atrophy, choroidal neovascularization, or both. ${ }^{12}$

Eye colour: Hyman et $\mathrm{al}^{24}$ found that brown eye colour was associated with less AMD. Frank et $\mathrm{al}^{25}$ concluded that Caucasians with light-coloured irides have a higher prevalence of AMD than people with darker coloured irides.

Concurrent conditions: AREDS investigators found a correlation between AMD and concurrent conditions, such as hyperopia, ${ }^{12}$ diabetes, ${ }^{26}$ and a history of cardiovascular disease. $^{26}$

\section{Modifiable risk factors}

Smoking: Of all modifiable risk factors, smoking is the most important. AREDS 3 and 19 found that smoking was associated with more severe cases of AMD (wet and dry). ${ }^{12,20}$ The exact mechanism of damage is unknown, but AREDS 3 authors noted that smoking lowers levels of circulating antioxidants. ${ }^{12}$ They proposed an underlying vascular basis for AMD, because smoking may damage choroidal vessels and alter choroidal blood flow, thus promoting atherosclerotic and hypoxic changes in the choroidal vessels. Smoking may directly cause vasoconstriction, increasing hypoxia and oxidative stress. ${ }^{12}$

Lifestyle factors: Lifestyle factors, such as diet, fitness, obesity, and socioeconomic factors, play a role in AMD. ${ }^{20}$

Sunlight: Another modifiable risk factor is exposure to ultraviolet solar radiation. Although evidence for the pathogenic role of sunlight exposure in AMD is controversial, it cannot be ignored. ${ }^{9,13,14}$

\section{Consensus}

- AMD is a multifactorial disease. The relative impact of environmental and genetic risk factors is unknown.

- Many risk factors for AMD are well known, as shown in the medical literature.

- There is a lack of clinical evidence to show that management of risk factors can prevent the progression of early AMD. Randomized controlled trials, such as AREDS, have not made any conclusive recommendations for patients with early (category 1 or 2) AMD.

- Randomized clinical trials, such as AREDS, have shown that the management of modifiable risk factors has an impact on advanced AMD. 
analysis. Trans Am Opbthalmol Soc 2005;103:173-84.

7. Gupta OP, Brown GC, Brown MM. Age-related macular degeneration: the costs to society and the patient. Curr Opin Ophthalmol 2007;18:201-5.

8. Sippy B, Hinton D. Aging of retina and retinal pigment epithelium. In: Agerelated macular degeneration. Lim JI, ed. NY; Marcel Dekker Inc., 2002.

9. van Leeuwen R, Boekhoorn S, Vingerling JR, Witteman JC, Klaver CC, Hofman A, et al. Dietary intake of antioxidants and risk of agerelated macular degeneration. JAMA 2005;294:3101-7.

10. Suzuki M, Kamei M, Itabe H, Yoneda $\mathrm{K}$, Bando H, Kume N, et al. Oxidized phospholipids in the macula increase with age and in eyes with age-related macular degeneration. Mol Vis 2007;13:772-8.

11. Kamei M, Yoneda K, Kume N, Suzuki M, Itabe H, Matsuda K, et al. Scavenger receptors for oxidized lipoprotein in age-related macular degeneration. Invest Ophthalmol Vis Sci 2007;48:1801-7.

12. Age-Related Eye Disease Study Research Group. Risk factors associated with age-related macular degeneration. A case-control study in the age-related eye disease study: Age-Related Eye Disease Study Report Number 3. Ophthalmology 2000;107:2224-32.

13. Taylor HR, Munoz B, West S, Bressler NM. Visible light and risk of agerelated macular degeneration. Trans Am Ophthalmol Soc 1990;88:163-73.

14. Hyman L, Neborsky R. Risk factors for age-related macular degeneration: an update. Retina and vitreous disorders. Curr Opin Ophthalmol 2002;13:171-75.

15. Age-Related Eye Disease Study Research Group. A randomized, placebocontrolled, clinical trial of high-dose supplementation with vitamins $\mathrm{C}$ and $\mathrm{E}$, beta carotene, and zinc for age-related macular degeneration and vision loss: AREDS report no. 8. Arch Ophthalmol 2001;119:1417-36.

16. Age-Related Eye Disease Study Research Group. The relationship of dietary carotenoid and vitamin A, E, and $\mathrm{C}$ intake with age-related macular degeneration in a case-control study. AREDS Report No. 22. Arch Ophthalmol 2007;125:1225-32.

17. Tan JS, Wange JJ, Flood V, et al. Dietary antioxidants and the long-term incidence of ARMD: The Blue Mountain Eye Study. Ophthalmology 2007;115:334-41.

18. Moeller SM, Parekh N, Tinker L, et al. CAREDS Research Study Group. Associations between intermediate ARMD and lutein and zeaxanthin in the Carotenoids in Age-related Eye Disease Study (CAREDS): ancillary study of the Women's Health Initiative. Arch Ophthalmol 2006;124:1151-62.

19. Delcourt C, Carriere I, Delage M, et al., POLA Study Group. Plasma lutein and zeaxanthin and other carotenoids as modifiable risk factors for agerelated maculopathy and cataract: the POLA study. Invest Ophthalmol Vis Sci 2006;47:2329-35.

20. Seddon JM, Ajani UA, Sperduto RD, Hiller R, Blair N, Burton TC, et al. Dietary carotenoids, vitamins A, C, and $\mathrm{E}$, and advanced age-related macular degeneration. Eye Disease Case-Control Study Group. JAMA. 1994;272(18):141320. Erratum in: JAMA 1995;273(8):622.

21. Chong EW-T, Wong TY, Krels AJ, Simpson JA, Guymer RH. Dietary antioxidants and primary prevention of age-related macular degeneration: systematic review and meta-analysis. Available: http://www.bmj.com/ cgi/content/short/335/7623/755 (published 8 October 2007). Ref \# doi:10.1136/bmj.39350.500428.47.

22. Seddon JM, Cote J, Page WF, Aggen SH, Neale MC. The US twin study of agerelated macular degeneration: relative roles of genetic and environmental influences. Arch Ophthalmol. 2005;123(3):321-7.

23. Haines JL, Spencer KM, PericakVance MA. Bringing the genetics of macular degeneration into focus. PNAS 2007;104:16725-26.

24. Hyman LG, Lilienfeld AM, Ferris FL 3rd, Fine SL. Senile macular degeneration: a case-control study. $A m \mathrm{~J}$ Epidemiol 1983;118:213-27.
25. Frank N, Puklin JE, Stock C, Canter LA. Race, iris color, and age-related macular degeneration. Trans Am Ophthalmol Soc 2000;98:109-15.

26. Clemons TE, Milton RC, Klein R, Seddon JM, Ferris FL 3rd; Age-Related Eye Disease Study Research Group. Risk factors for the incidence of advanced age-related macular degeneration in the Age-Related Eye Disease Study (AREDS). AREDS report no. 19. Ophthalmology 2005;112:533-9.

27. Health Canada. Canada's Food Guide 2007. Recommended number of food guide servings per day. Available: http://www. hc-sc.gc.ca/fn-an/food-guide-ailment/ order-commander/eating_well_bien_ manger_e.html. (accessed 2007 Sept 13).

28. Statistics Canada. Table 105-0449. Fruit and vegetable consumption, by age group and sex, household population aged 12 and over, Canada, provinces, territories and selected bealth regions (June 2005 boundaries), every 2 years (175392 series). Available: http:// cansim2.statcan.ca/cgi-win/cnsmcgi. exe?Lang $=\mathrm{E} \&$ RootDir $=\mathrm{CII} / \&$ Res ultTemplate $=\mathrm{CII} / \mathrm{CII} \_\&$ Array_ Pick $=1 \&$ ArrayId $=1050449$. (accessed 2007 May 28).

Key words: age-related macular degeneration, prevention, degenerative eye disease, antioxidant supplements, ocular supplements, risk. factors, consensus, guideline

Sohel Somani, MD, Toronto, Ont.; Ann Hoskin-Mott MD, Halifax, N.S.; Adit Mishra MD, Halifax, N.S.; Alain Bois' OD, Longueuil, Que.; Brian H. Book, OD, Winnipeg, Man.; Mark Chute, OD, Elmsdale Vision Centre, Elmsdale, N.S.; Ronald Gaucher, OD, Regina, Sask.; Barry Winter, OD. Toronto, Ont.

The paintings used to illustrate this article, are by Adam Hahn. For more information about his work on macular degeneration, please see page 40. 
Table 1: Estimated Number of Canadians affected by AMD

\begin{tabular}{l|c|c|}
\hline Age (Years) & $\begin{array}{l}\text { Percentage(\%) } \\
\text { with AMD }\end{array}$ & $\begin{array}{l}\text { Canadians } \\
\text { with AMD* }\end{array}$ \\
\hline $43-53$ & 8.5 & 467,500 \\
$55-64$ & 14.4 & 529,126 \\
$65-74$ & 19.4 & 440,768 \\
$\geq 75$ & 36.8 & 748,512 \\
Estimated total & & $2,185,906$ \\
\hline
\end{tabular}

* Extrapolated from Beaver Dam Eye Study 1988-1990³

Population statistics for age groups <65: Statistics Canada 2006 Census;

For age groups $>65$, Statistics Canada projections (medium growth), 2005
Table 2: Percentage of Canadians in 2005 who ate $<5$ servings/day of fruit and vegetables

\begin{tabular}{|l|c|}
\hline Age (Years) & Percentage(\%) \\
\hline $45-54$ & 56.8 \\
$55-64$ & 52.3 \\
$65-74$ & 48.5 \\
$\geq 75$ & 39.4 \\
\hline
\end{tabular}

Statistics Canada. Table 105-044928

\section{Pathogenesis of AMD}

Flourescein Angiograms

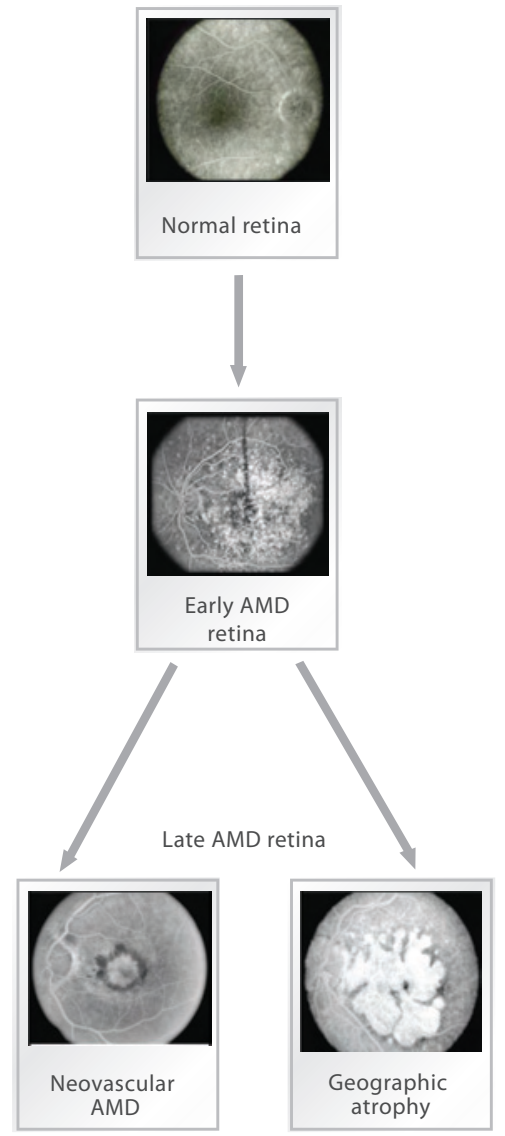

\section{Oxidative Stress}

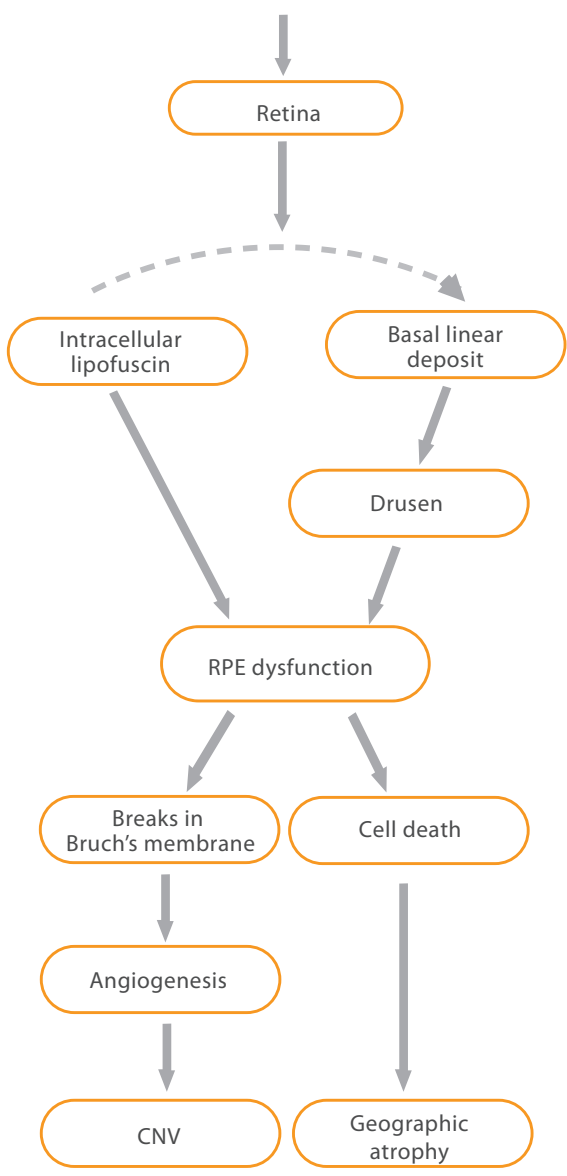

Complement activation

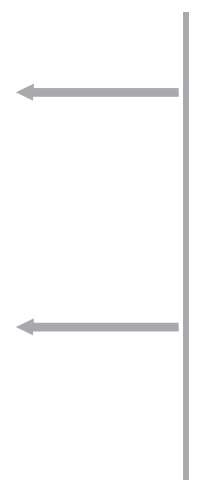

Inflammation

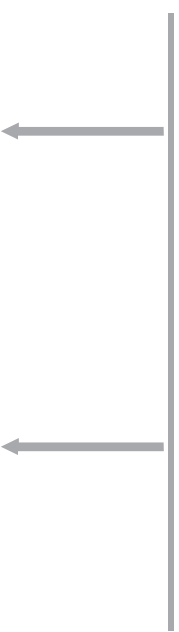

CNV $=$ Choroidal neovascularization 


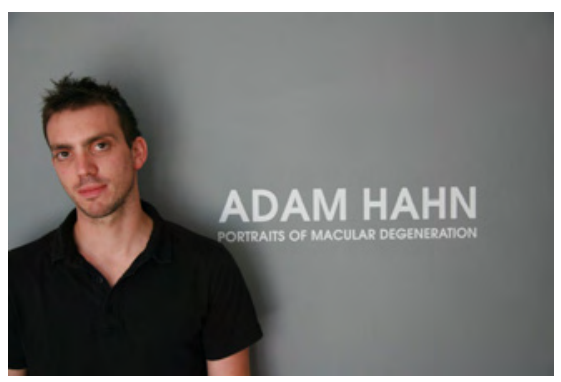

Adam Hahn graciously allowed us to use his work to accompany the feature article on age-related macular degeneration.

Adam Hahn is an established portrait painter who has twice been selected for the BP Portrait Award at the National Portrait Gallery in London, England. He studied at the Glasgow School of Fine Arts and the Prague Academy of Arts, Architecture and Design.

With the assistance of The London (UK) Project to Cure Blindness he spent a year with his portrait subjects for this project, patients suffering from macular degeneration. His series captures the subjects as they see themselves through the fog of partial blindness. The viewer is engaged in trying to understand how someone with macular degeneration sees the world.

To see more of Adam's work: www.adamhahn.co.uk
The inspiration for the work was my grandmother. She had MD for the last eight years of her life but like so many people with MD she never really spoke about it so we never really knew what she could or couldn't see. We would read her newspaper articles, help her with her post and finances but she was an incredibly independent person who could do more in one day than I could in a week! Although she couldn't recognize faces or read type, she never let her eye sight interfere with her life. She was constantly on the go, walking up to eight miles every Sunday, forever going to concerts, theatres, music groups, classes, exhibitions, and cinema, and she also helped as a volunteer at her local hospital.

So after she died (almost three years ago) I decided to do something in her memory by raising awareness of $\mathrm{MD}$. I contacted the Institute of Ophthalmology and the London Project who gave me the scientific information necessary to understand the disease, but I needed people's experiences to truly understand what it's like to live with MD. The MD Society put me in touch with two of their members and the MD group in Tunbridge Wells, southeast of London.

On meeting each person I asked them to describe in as much detail what they saw of

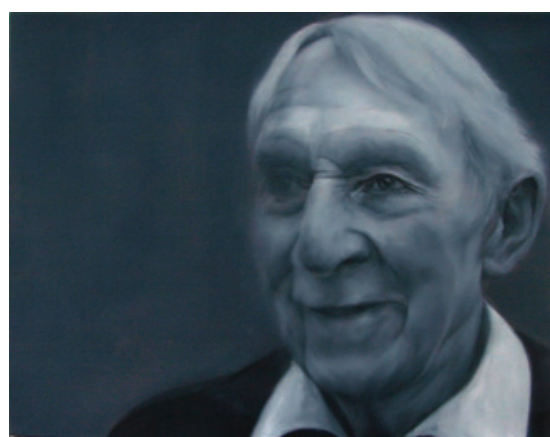

'Richard', by Adam Hahn

me. I kept the distance constant for each sitter to get a clear idea of the information their eyes received. After taking photographs at the sitting, I transferred this information by manipulating the image to a level of vision described by each sitter. In the case of my grandmother's portrait Booba, (see page 14). I worked on the basis of what other sitters had told me of their vision and how that related to what she saw and how she used her peripheral vision. Not only was I trying to raise awareness but I was also challenging the scientific images where MD vision is represented as a circular black hole in the centre of one's vision, that no sitter related to.

Adam Hahn

\section{International Conference} on Light and Vision

Basic \& Advanced Classes in Optometric Phototherapy

Certification for basic course in Syntonic Phototherapy available

April 30 - May 2, 2009

Fallsview Marriot

Niagara Falls, Ontario

Contact: Ron Wahlmeier, Admin Director Phone: 1-719-486-0190;

syntonics@breshan.net

or visit the Syntonics website www.syntonicphototherapy.com

\section{PAR-MED PROPERTY SERVICES INC.}

PAR-Med is the recognized leader in property management of medical office buildings in Ontario. Opportunities exist within our portfolio for optometry services and dispensing.

TELEPHONE 416-364-5959 x403 1-800-663-5340

EMAIL: info@par-med.com www.par-med.com 